\title{
O som ao redor: arqueologia do vertical moderno no Recife
}

\author{
Ismail Norberto Xavier' \\ https://orcid.org/0000-0002-1098-4950 \\ I - Escola de Comunicação e Artes - USP \\ São Paulo (SP), Brasil
}

Resumo: Este artigo analisa a composição narrativo-dramática de $O$ som ao redor (Kleber Mendonça Filho, 2012) como forma de evidenciar os estratos do tempo que convivem num bairro moderno do Recife; há acento especial dado a relações de classe encenadas em tom de crônica, mas gradualmente adensando as tensões criadas entre as personagens. No percurso, está lá visível um estilo de arquitetura e uma forma dos bem nascidos administrarem sua segurança privada.

Palavras chave: estratos do tempo; relações de classe; cidade moderna, segurança privada.

\begin{abstract}
The sound around ( 0 som ao redor): archeology of the modern vertical in Recife - This paper analyses the film Som ao redor (Kleber Mendonça, 2012) focused on the way its narrative and visual style give emphasis to the different layers of time that interact in a Recife's modern and verticalized neighborhood. In a comic-dramatic tone the film deals with clear tensions involving opposed social classes, tensions that have something to do with the way people from the higher social stratum deal with their private security.
\end{abstract}

Keywords: layers of time; class relationship; modern city; private security.

\section{O passado no presente}

O som ao redor, de Kleber Mendonça (2012), pelos seus aspectos formais e temáticos, se caracteriza como um ponto de convergência que permite, em retrospecto, nova articulação de um conjunto de filmes pernambucanos da 
"retomada" que, em formas narrativas distintas, trabalhou motivos centrais aí presentes, como a relação entre passado histórico e presente, tradição rural e modernização urbana, marcos balizadores de relações de classe e de gênero.

Nesta lida com o cotejo entre o passado e o presente, há no filme de Kleber uma arqueologia que permite observar as camadas de tempo que se acumulam no tecido social da grande cidade, evidenciando a sobrevivência de relações de poder e for mas de sociabilidade que outros filmes tematizaram ao colocar em foco personagens que fazem um movimento da cidade grande para o interior, encontrando uma ordem social e relações de família que os desafiam, marcando uma diferença de referenciais na condução da vida. Essa diferença vale como um confronto entre distintos momentos históricos, ativado por um conjunto de motivos narrativo-dramáticos que incidem sobre a forma de trabalhar com gêneros do cinema.

Este vai e vem cidade-campo pode ser fruto de um incidente, como no caso da incursão de uma adolescente de classe média urbana no mundo do outro de classe (numa passagem do urbano ao rural), que faz da travessia por um território social desconhecido um romance de formação, como ocorre em Eles voltam, de Marcelo Nordello (2011). Em Boa sorte meu amor, de Daniel Aragão (2013), seguimos o percurso de figura masculina que, à procura de sua amada em função de sua misteriosa ausência, viaja do Recife para o interior e adentra a região onde moram os pais dela, para então ver frustradas suas indagações, num terreno marcado pela violência de uma tradição patriarcal tal como vivida por uma família socialmente acanhada, o que, para o jovem urbano, ele próprio herdeiro da Casa Grande, é um retorno ao locus de uma tradição moralista em sua versão ressentida, vinda dos que estão fora da esfera do poder. ${ }^{1}$ Há os casos de um movimento contrário, no qual o percurso de uma moça de província é marcado pela complementaridade entre duas violências - a vivida no interior (exploração sexual na esfera doméstica) e a vivida na grande cidade, em que, migrante vulnerável, ela se torna mercadoria, como em Deserto Feliz, de Paulo Caldas (2007), e Baixio das bestas, de Cláudio Assis (2006). Árido Movie, de Lírio Ferreira (2006) traz outra variante com a figura do jovem âncora do noticiário de uma grande rede de TV que, vivendo em São Paulo, recebe a notícia da morte do pai. Ele

1 O filme de Daniel Aragão é posterior ou simultâneo a O som ao redor, mas vale esta referência no painel que atesta a presença do motivo temático do "passado no presente" no cinema contemporâneo realizado em Pernambuco. 
volta à sua cidade natal no interior de Pernambuco, e enfrenta a pressão familiar para que assuma a tarefa que lhe cabe segundo a lei da tradição: a vingança do pai assassinado.

Baile perfumado, de Paulo Caldas e Lírio Ferreira, cujo impacto em 1996 marcou o início desta constelação de filmes, é um exemplo desse cotejo passado-presente tal como trabalhado no plano do próprio estilo, ao tratar a experiência do cangaço numa chave que incorpora o espírito Mangue Beat, incluindo trilha sonora com a presença de Chico Science. O filme, em sua dimensão historiográfica, presta homenagem ao cineasta pioneiro Benjamin Abrahão, imigrante que realizou a façanha de filmar Lampião e seu bando no sertão nos anos 1930. Exibe o material de arquivo que traz as preciosas imagens documentais dos cangaceiros, alternando-as com o andamento de sua trama ficcional marcada por uma feição pop que ativa uma iconografia e uma sonoridade modernas. Esse encontro com a tradição popular do sertão nos surpreende quando vemos Lampião, Maria Bonita e os cabras a dançar, em cenas que evidenciam o acesso dos cangaceiros a um circuito amplo de mercadorias que inclui perfumes e bebida importada. Testemunhamos o baile perfumado que evidencia não um mundo isolado, mas amplo leque de conexões que tem um momento decisivo nesse contato com o cinema. Foi um momento de consagração ampliada que o filme de Abrahão Ihes propiciou e, na contracorrente, mobilizou forte pressão do Governo Central para sua captura e morte.

Considerada essa constelação, O som ao redor assume uma posição estratégica no processo, ao retrabalhar esse motivo reiterado no cinema pernambucano recente. Uma de suas forças é justamente gerar um movimento retrospectivo inovador na conexão entre cidade e campo, passado e presente. Vale, nesse destaque, a consistência de sua opção formal e do modo como tais motivos recorrentes encontram nele sua expressão mais aguda, considerada a lida com a arqueologia dos espaços da modernidade, como acumulação de tempos históricos que se justapõem, convivendo de forma singular em plena grande cidade.

O teórico da historiografia Reinhardt Kosellek (2014) trabalha a noção de estratos de tempo, que diz respeito ao decurso que envolve camadas simultâneas que não se movimentam de modo idêntico, comportando distintos ritmos de manifestação num processo que depende das escalas de observação. Algo pode se dar como fato contingente quando observado dentro 
do escopo da vida de um indivíduo. Porém, quando observado em outra escala envolvendo uma ordem mais ampla de acontecimentos - no limite, toda uma ordem social - pode ser visto como fato regular, algo característico dela. Os estratos interferem um no outro dentro de uma topografia de tempos que se superpõem na história, dada a diferença de ritmo entre as distintas esferas de acontecimentos que fluem simultaneamente, gerando "sobrevivências" de uma ordem passada numa esfera da vida social enquanto noutra já há uma nítida distância face ao que se considera como próprio a uma ordem superada.

Em O som ao redor, o paradigma patriarcal e as questões de classe não se articulam como relação entre o urbano, como ícone do moderno, e o rural, como locus do arcaico, uma vez que é no próprio seio da grande cidade que se acentua, num ponto avançado da verticalização e da sociedade afluente, a presença hoje de formas de poder e de relações de classe supostamente arcaicas. A experiência contemporânea recolhe aí os dados de uma modernização truncada.

\section{A crônica do bairro}

Kleber conduz de forma notável a encenação da vida de um bairro da alta classe média do Recife, de modo a caracterizar a permanência do passado, ou seja, a vigência de tradições patriarcais de mando e coronelismo. O filme compõe um painel de personagens e situações que se sucedem como fatias de um cotidiano que, no andamento sem pressa da crônica, tipifica com muita nitidez o território esquadrinhado por uma notável mise-en-scène feita de deslizes, trocas de olhares e silêncios que introduzem o insólito no cotidiano.

Antes de mergulhar nesse mosaico e suas pequenas tramas, o filme traz na sua abertura - no momento dos créditos - uma montagem de fotos de arquivo que traz uma série de imagens que evocam a história da zona rural de Pernambuco, com imagens da Casa Grande e da senzala, retratos da vida comum e de festejos. Há uma cronologia nesse painel de fotos, havendo movimento em direção a momentos de confronto mais recentes, com destaque para as imagens referentes às lutas das ligas camponesas em torno de 1960.

Composta essa moldura histórico-temática, mergulhamos no contemporâneo: a cena de uma manhã ensolarada num condomínio. Seguimos uma menina de patins pela área da garagem do prédio e chegamos à área de 
lazer, que está bem animada, com meninos jogando bola ou na piscina. Tal momento, com nítido sabor de feriado, contrasta com o forte ruído de uma maquineta a vibrar nas mãos de um operário que trabalha no espaço contíguo à área de lazer. Temos aí o primeiro momento em que uma cena de tranquila sociabilidade de moradores é tensionada por uma presença que compõe uma dissonância. Esse forte ruído só se dissolve quando planos de transição - o asfalto com uma declaração de amor para ser lida da sacada de um apartamento, a vista de prédios da região, namorados que se beijam num espaço murado entre os edifícios - nos levam à imagem de uma ocorrência fortuita do dia a dia: um carro se afasta da câmera em baixa velocidade e se dirige para a esquina que está no ponto de fuga; lá, encontra outro vindo na transversal, que também parece em ritmo de passeio, e, de forma inusitada, os dois carros se chocam. O que gerou o acidente? Um cochilo? O excesso de confiança na aparente pasmaceira à volta? O choque, nem bem consumado, é logo suprimido pelo corte seco que traz o mesmo plano dessa rua à noite e a inscrição "Primeira parte: Cães de guarda".

É assim anunciado o primeiro dos três atos desta comédie dramatique habitada pela fórmula "tudo em paz, porém há algo que, de repente, pode vir ao centro da cena". Se vier, no entanto, não se fará de todo visível, pois não será necessário. Esse primeiro lance minimalista de choque inesperado pode ser observado como a célula discreta de um tecido complexo que levará a muito além suas formas de contaminação do trivial cotidiano pelo insólito.

\section{Cães de guarda}

A indicação do letreiro é seguida literalmente, pois advém de imediato o episódio que introduz a figura de Bia e sua família de classe média em ascensão, mas que parece estar ainda por consolidar seu status socioeconômico, portanto, menos remediada do que a maioria dos seus vizinhos. Nessa cena noturna, nós a encontramos insone, exasperada com os latidos do cão no quintal do vizinho, uma versão literal do som ao redor que dá ensejo à comédia alimentada pelos seus curiosos estratagemas na luta pelo silêncio. Esta inclui jogar pela janela uma pílula de sonífero para o cão ingerir, o que dá certo. Tem início a crônica familiar cujos episódios compõem um subplot que pontua a progressão da narrativa central que envolve João, seu avô Francisco, dono de um engenho, e sua família. A presença peculiar de Bia ao longo do filme dá a nota de humor em lances inusitados, marcando um contraponto de idiossincrasia e leveza ao que de mais dramático 
ganhará realce na crônica do bairro. Personagem de destaque, ela tem suas performances solo, como a masturbação com o sexo apoiado na quina da máquina de lavar roupa que vibra com o motor ligado ou seu esquema de disfarce quando fuma um baseado expirando a fumaça no cano de um aspirador de pó para evitar que o cheiro se espalhe; e tem os variados lances da vida doméstica com seu marido (este sempre em segundo plano) e o casal de filhos. As crianças e a sua empregada formam com ela uma parceria no tempero do dia a dia, não excluídas as visitas de um entregador de gás - e também de maconha - e de um professor de chinês que vem dar aulas particulares para as crianças, numa medida de "atualização", preparo para a vida futura, anseio que se debate no cotidiano com o humor instável que solicita zonas de escape. A variedade de situações jocosas não exclui momentos em que seu comportamento entra em sintonia com o dos vizinhos chiques no trato da empregada num rompante de insatisfação com qualquer deslize.

Do episódio noturno de Bia com o cão de guarda, saltamos para a cena de João no seu apartamento, onde dormiu com a namorada Sofia ainda estão deitados no sofá da sala. Eles correm para o quarto quando ouvem a empregada que chega, mas esta ainda os vê passar, sorrindo com ar maternal de quem faz parte da família há muito tempo; neste ambiente, é natural a presença dos filhos dela, adultos, que vêm para fazer um serviço ou outro, e há as netas que sentam no sofá para assistir à TV. Cúmplice do jovem patrão, ela conhece as regras, sabe toda a história, como vemos na sua conversa com João e Sofia na hora do café. Essa é a primeira observação sobre a relação entre quarto de empregada, área de serviço e sala de visita, algo que veremos se reiterar nas cenas domésticas da família em suas várias propriedades, seja neste apartamento de João, no de seu avô Francisco ou no de seu tio.

O avô é proprietário de muitos apartamentos e de casas remanescentes do bairro que ainda não foram vendidas para empreiteiras, que as colocarão abaixo para seguir na marcha inexorável da verticalização. João é o corretor que trabalha para o avô na negociação das propriedades. Mais tarde veremos que Sofia havia herdado uma casa no quarteirão, na qual ela morou por pouco tempo no passado, que foi vendida há alguns anos. Está agora de passagem e João, que sabe estar sua antiga casa de novo à venda para abrigar uma nova torre, a leva para uma última visita. Ela comenta as mudanças do bairro, que avança em sua feição burguesa nouveau riche, com forte presença do seu Francisco, o Senhor de Engenho já instalado na cidade e com eventuais retornos às suas terras, em temporadas de repouso. 
No papo matinal com a empregada, vamos sendo informados das coordenadas familiares e do estatuto do clã neste território, até o momento em que a conversa muda de tom quando é trazida a informação de que o carro de Sofia teve o seu tocador de CDs roubado. Nesse momento, João fala sobre seu primo Dinho, que tem lá suas perversidades de moço rico de família poderosa: ele suspeita ter sido ele quem roubou o aparelho. Isso é confirmado quando João conversa com os "flanelinhas" que estão na rua durante o dia, mas têm ouvidos para o que circula. Ele vai ao apartamento do primo e o pressiona para devolver o objeto. Esse incidente que pontua a apresentação de João e seu mundo é um dos pequenos episódios que expõe o teor das relações entre proprietários e prestadores informais de serviços, que definem os pontos extremos de uma estratificação social observada no território.

Na sucessão de imagens do bairro, há o momento em que a câmera se instala na cobertura de uma das torres para seguir João em seu trabalho de corretor, nos trazendo a vista da massa vertical e seu efeito urbano catastrófico, somado à vista de uma favela nas adjacências. E há uma variedade de imóveis que incluem habitações ainda menos imponentes, que indicam as nítidas diferenças de classe e de poder de consumo que define os termos do convívio no bairro

João e seus movimentos funcionam como um mediador neste mapeamento e na apresentação das personagens que compõem a sua família e de outras figuras que desenham o perfil dos que circulam pelo bairro, inclusive os interessados em comprar imóveis. Como parte dos episódios curiosos, na conversa com uma cliente para quem mostra um apartamento, ele inclui a referência de que houve ali o suicídio da ex-moradora, ao que ela responde com a pergunta se isso não deve acarretar um desconto no preço do imóvel, numa passagem rápida para o interesse em meio ao seu teatro de consternação pelo ocorrido.

Em foco a questão da segurança, a tônica é a privatização, nos prédios e na área pública, e o tom das relações se torna mais tenso e cheio de reticências na medida em que o painel avança, até o momento em que entram em cena Clodoaldo e seus dois amigos, que chegam para formar uma equipe de guardas noturnos. Antes de tudo, precisam oferecer sua proteção aos moradores. Essa nova presença marca um ponto de inflexão na tonalidade da mise-en-scène. 
João visita seu tio e comenta os últimos lances do primo Dinho, mas logo a conversa segue outros caminhos. Eles são interrompidos pela chegada de Clodoaldo, que toca a campaninha e é recebido pelos dois na frente da casa junto à pequena cerca que a separa da rua, lugar destinado a quem está lá para vender seus serviços de segurança. Ele tem boa lábia e conduz bem a conversa com os proprietários, sendo às vezes digressivo, sempre com um misto de simpatia e ironia em suas respostas. Depois de indagações e reticências, o pai de João termina por aceitar a proposta do pagamento mensal. Quando o segurança se afasta, pai e filho se olham e seus gestos mantêm uma indagação que reforça o senso de que nem tudo é tão simples, mas isso logo se dissolve e a vida continua.

Na conversa, menção enfática foi feita pelos donos da casa ao Seu Francisco e sua influência no bairro, dado que Clodoaldo confirmou e, com um sorriso, disse estar já bem a par das regras do jogo local. A visita ao avô de João tem logo lugar, com os seguranças entrando pela área do serviço do prédio em que ele mora e tendo a conversa na cozinha, todos de pé. Há um reconhecimento mútuo da linguagem que trazem de outras paragens e a visita responde bem a desafios do dono da casa. Este deixa claro quem manda no bairro e é enfático na ordem para que "não mexam com Dinho, ele é problema meu". Mais para o final da conversa, ele provoca um dos parceiros de Clodoaldo com um comentário sobre a sua condição de caolho como eventual problema para a função a ser assumida, recebendo como resposta a referência a Lampião, num embate com réplica e tréplica sem subserviência. Seu Francisco sorri ao dizer "gostei deste cabra", selando o código comum que os aproxima na oposição de classe. Em suma, uma conversa feita de sorrisos, porém tensa. Os seguranças passam no teste e saem de lá com a benção do mandachuva local.

Não demora e seu Francisco telefona para seu neto, que está na cobertura de um prédio cumprindo sua tarefa de corretor. A câmera permanece a seu lado e só ouvimos a sua parte do diálogo. Ele comenta algo do trabalho, mas o tom da conversa é de assuntos de família, havendo a promessa do neto de ir visitar o engenho.

\section{Guardas noturnos}

A primeira cena do segundo ato se passa na casa de Bia, com a família à mesa em conversa que tem, ao lado dos assuntos ligados à gerência da 
educação dos filhos, o comentário sobre Clodoaldo e sua forma de chegar bem no momento em que teria havido uma dose maior de furtos no bairro, como se ele estivesse por trás do acontecido para preparar o que de chantagem haveria em sua oferta de segurança para os moradores. Enfim, tudo em volta é conspiração.

Já estamos em novo clima no andamento da trama depois de as primeiras cenas envolvendo a equipe de Clodoaldo terem mudado a feição dos subentendidos, pois cada novo episódio passa a tensionar as relações. Essa é uma opção de estilo que vai ganhar maior ênfase no final que intensifica a presença do tempo esgarçado nas conversas e também nos planos de transição com seus espaços vazios, um dispositivo que vem junto com a notável modulação de silêncios e do "som ao redor", que tonifica na presença "do plano a mais", em que a câmera insiste em focalizar a cena num momento em que ela parece estar terminada. O filme vai criando, assim, o clima de "estranho familiar" e de tensão, até que no final venha à tona uma das tramas subjacentes que, quando emerge, é resolvida em direção inesperada.

A trama a passos lentos e as supostas digressões que dão andamento à crônica do bairro vão compondo uma imagem do território que, sem dispensar os lances de humor, assenta a sua arqueologia na tensão entre as classes que, no presente, reproduzem formas de mando senhoriais que marcam a sua permanência ao longo do filme, desde a evocação trazida pelas fotos na abertura.

Um crescente mal-estar se insinua, tanto pelos lances no espaço público, quanto pelos jogos de inveja que temperam o consumismo, desde a cena em que Bia é vítima da agressão intempestiva da sua irmã quando esta se dá conta de que ela fez a compra de um televisor de 24 polegadas, enquanto ela, a irmã, só conseguiu comprar um mais modesto. Pequenos conflitos como esse compõem a comédia que pode vir da reação histérica movida pelo ressentimento, ou pode vir de um achaque arbitrário quando os seguranças, em plena luz do dia, interpelam um passante na calçada como se fosse uma infração caminhar por ali. Quando ele expõe a sua razão para a caminhada, mobilizam walk-talkies e sondagens para confirmar a versão dada, um aparato fora de propósito e ridículo que alimenta um senso constante de ameaça, fonte de receita dessa pequena indústria do medo. Os que prestam serviço para os donos da rua precisam reforçar ações que revelem o quanto a violência endêmica na cidade está ali na esquina, a qualquer hora 
e, dada a propalada ausência do Estado no território, deve ser controlada pelos ricos num afã de autodefesa que se mostra uma versão menos explícita, mas de natureza semelhante ao que hoje se define como a "cultura do condomínio", segundo Cristian Dunker (2015).

No prédio onde mora, João participa de uma reunião de condomínio que exibe os ressentimentos e a arrogância dos comentários quando o tema é a possível dispensa do porteiro que fica na recepção à noite. Um morador exibe com orgulho as imagens que seu filho, uma criança, captou do funcionário dormindo na recepção e outra moradora indignada reclama do fato de sua revista Veja ter sido entregue sem o plástico. João traz argumentos contra a dispensa, não recebendo apoio; na hora da decisão, o celular toca, ele atende e se retira sem participar da votação. Não era importante. O principal era ir ao encontro de Sofia, corroborando sua postura de não se envolver até o fim com a questão social ali implicada, não obstante sua simpatia pelo funcionário.

Colocada em pauta a questão da segurança, esta se expõe em O som ao redor como mais um aspecto da problemática de fundo que tem mobilizado cineastas que, guardadas as diferenças de estilo, exploram certos motivos dramáticos, justapondo as camadas de tempo que se acumulam na experiência contemporânea de modernização incompleta, marcada pelas permanências do mundo do "homem cordial", de gentileza com os "seus" e mandonismo e violência com os "outros", lembrando a formulação de Sérgio Buarque de Holanda (1997). É um mundo que trava a formação da cidadania, embaraIhando o público e o privado, repondo a hegemonia de classe e as tradições patriarcais de mando na vida da cidade.

Dentro dessa privatização dos embates, Clodoaldo oferece um exemplo de tática mais ofensiva, que vem do subalterno e usa recursos táticos de confronto mais direto, que, não obstante, incorporam uma franja de ambigüidade. Ele não se resume a assumir seu ponto de olhar e de escuta na rua, no seu estilo cheio de maneiras e da fala daquele "que se supõe saber". Num certo momento, ele parte para o desafio a Dinho, o primo de João, com uma ligação anônima feita do orelhão da rua em que, de forma ofensiva, o desqualifica pelos lances de cleptomania e o ameaça de modo enfático. Só poderia ser dele essa ligação ousada e, em resposta, o moço rico não demora a caminhar até o abrigo dos guardas noturnos na rua para mostrar que sabe muito bem quem ligou para ele e devolver a ameaça apoiada no 
seu poder vicário amparado na família. Sua fala, no entanto, não vai além de uma precária exibição do orgulho e do preconceito de classe que só faz evidenciar sua insegurança e precariedade.

Escurece a tela e a repetição do plano da rua vazia à noite traz nova ocorrência insólita, com um carro a dar um cavalo de pau na esquina. Passamos ao letreiro "Guarda-costas", que nos leva ao terceiro ato, quando João e namorada finalmente pagam a visita prometida ao avô que está no engenho.

\section{Guarda-costas}

A ida ao engenho é ocasião para o descanso na rede da varanda, o almoço tranquilo em que o avô não resiste em perguntar quando será o casamento para testar o teor deste namoro. João não hesita e diz "vamos com calma". Não é para tanto esse caso que, como veremos, logo terá fim, no momento em que a namorada encerrar sua temporada no bairro, embora haja sinais evidentes do envolvimento dele com ela. Mais tarde, na seqüência final do filme, na grande festa de aniversário de uma das netas de Seu Francisco, João dirá meio sem graça ao primo Dinho que tudo acabou entre ele e Sofia, pois "ela tinha outra história".

A visita ao engenho se faz do relaxamento e de uma visita guiada pelas ruínas ao redor, seja num depósito com a sucata dos velhos equipamentos não mais em uso, seja pelas ruínas de um cinema local que tinha fachada imponente e ora se reduz a um passeio bem humorado como se das ruínas viesse o som de um filme de horror. Em cena, vale a brincadeira de Sofia a assustar João nas ruínas do cinema. Essa alusão jocosa ao horror ganha uma rima no plano seguinte, quando vemos os dois jovens e Seu Francisco a tomar um banho embaixo de forte queda d'água, cena que no seu final destaca João a receber o jato de água tingido de vermelho, escancarando efeito especial que flerta com o gênero e como que culmina a invasão do insólito no fluxo natural já presente em passagens anteriores. Está preparado o clima da sequência seguinte.

Desta imagem de João na cachoeira, tomando o "banho de sangue" com a boca aberta e o olhar dirigido à câmera, saltamos para o apartamento no Recife onde o vemos na cama, acordado ao lado de Sofia. Ela dorme e ele, com ar de recém-desperto, está pensativo. Um lance que sugere a pergunta do espectador ansioso por explicações: teria a cena da cachoeira sido um sonho? Não demora e vemos uma menina, filha da faxineira, que encostada 
na soleira da porta aberta olha para ele a sorrir, alterando a atmosfera da cena antes que as nossas especulações sobre a cachoeira ganhem curso.

Essa forma de dissolver um impulso de ansiedade interpretativa terá mais adiante uma versão mais elaborada, na qual estranhamento e senso de ameaça ganharão maior espessura. Retornamos à casa de Bia em nova cena noturna, desta vez para acompanhar a relação com sua filha Fernanda, que dorme enquanto imagens e ruídos sugerem uma invasão das casas do bairro. Ela acorda e observa o movimento da janela do quarto. Essa passagem alude ao que poderia ser uma ação coletiva dos moradores de uma favela próxima. A cada plano, eles vão se tornando mais numerosos na ocupação do terreno contíguo. A montagem alternada entre Fernanda e a cena ao redor sugere, de início, um pesadelo, seguido do despertar, como experiência noturna de menina insegura que, ao som cada vez mais forte dos ruídos, se dirige ao quarto dos pais e encontra a cama vazia. Quando ela volta ao seu quarto, um movimento de câmera centra foco na cama vazia, preparando o corte seco para uma nova imagem dela dormindo. Tudo um sonho? É o que parece, mas a estranheza na montagem e o tom furtivo da observação renovam um estilo que marcou o regime noturno das imagens e dos sons, calibrados para manter vivo um senso de ameaça, uma inquietação no ar associada aos temores das personagens.

Nessas passagens, em que se cria o estranhamento trazido pelo recurso a "atrações" inseridas a fórceps pela montagem, não temos um efeito dramático, uma vez que permanece ambíguo o estatuto desse tipo do evento-atração que termina por se dissolver sem deixar rastro. As ocorrências anteriores, nessa direção, foram muito breves, mas tiveram seu papel de, aos poucos, fazer deslizar o que antes tinha um tom de crônica do cotidiano e de escoamento do tempo para esse clima mais insólito. Por exemplo, houve a passagem muito rápida de um menino pelo corredor de uma casa do bairro no momento em que Clodoaldo, supondo estar ela vazia e tendo em mãos a sua chave, está lá a transar com a empregada do Seu Francisco num quarto. Mais adiante, outro menino - ou o mesmo? - foi visto pela insone Bia à distância, subindo no telhado do vizinho em plena noite, enquanto ouvimos um inquietante ruído vibratório e desagradável. Por duas vezes, o plano rápido e a distância não permitiram a clara identificação da figura, mas houve ainda outra cena noturna em que um menino foi surpreendido na rua em cima de uma árvore pelos dois guardas noturnos da equipe de Clodoaldo. Sendo negro e pobre, tornou-se a vítima escolhida 
para a agressão arbitrária, levando um soco no rosto para entender que "não deve voltar aqui".

O lance efetivo da trama que traz o "ponto de virada" no terceiro ato é a chegada do irmão de Clodoaldo, que, em cena anterior, o havia anunciado como vindo do Paraná e dissera aos amigos que eles dois tinham um assunto a tratar. Ao chegar, o irmão salta da garupa da moto que o trouxe e veste o colete dos guardas noturnos. Seu irmão o apresenta aos amigos. A cena da chegada se passa durante o dia. Sendo rápida e vista a distância, não ouvimos o diálogo, embora o início dela tenha sido acompanhado pela curiosa repetição do ruído off antes ouvido na cena noturna de Bia a observar as casas vizinhas de sua sacada.

Logo saltamos para a noite da grande festa de aniversário de uma das netas de seu Francisco, sequência que faz convergir os diferentes focos de interesse trabalhados ao longo do filme. Há o núcleo que se organiza em torno da família do patriarca que, uma vez reunida na casa de um dos seus filhos, compõe um autorretrato nos variados diálogos envolvendo diferentes gerações e suas formas de sociabilidade. O clima ameno da festa não exclui ironias a um estilo de vida e de formação dos jovens, agora ressaltado o seu contato com a ficção secretada pela televisão. Bia e sua família não fazem parte desse círculo social, mas sua presença na sequência final vem coroar sua condição de figura de contraponto que, no paralelismo das tramas, conduz o polo da comédia, um contraponto estratégico no momento em que tudo chegar à sua tensão máxima no mundo de Seu Francisco. Antes de cuidar da ciranda social no ambiente da festa, o filme a havia acompanhado em sua compra de uma caixa de bombinhas de alto calibre para se divertir com seus filhos.

Nessa noite, o avô da aniversariante tem pressa em resolver uma questão e interrompe sua presença na festa para atender a Clodoaldo, que viera até ali atendendo a seu chamado. O encontro se dá junto à cerca de entrada, no limite da rua, como na primeira conversa de João e seu tio com o guarda noturno. A presença do irmão de Clodoaldo traz um toque especial à cena pela tensão permanente em seu semblante desde que é apresentado a Seu Francisco. Já observamos um ou outro travo nas relações familiares ou entre as classes que compõem o painel do bairro, onde não estiveram ausentes as figuras do ressentimento. O irmão de Clodoaldo neste momento é quem recolhe essa carga, e sua presença vale como promessa de algo de mais grave no horizonte. 
Seu Francisco, de início, reclama do fato de não ter sido atendido quando ligou várias vezes para Clodoaldo, deixando recado. Sem demora, esclarece que precisa ter uma conversa com eles, definindo o encontro para dali a pouco lá no seu apartamento. Eles se despedem e voltamos à festa.

Chegado o momento do encontro, os guardas noturnos voltam a entrar pela área de serviço, mas desta vez a conversa se dá na sala, onde o anfitrião os convida a sentar. Ao explicar os motivos deste chamado, o senhor de engenho se refere a episódios violentos ocorridos em área de suas propriedades no campo, com destaque para o assassinato de seu ex-capataz. Isso indica possível ameaça a ele próprio, dado que o crime se insere numa engrenagem de vinganças, com toda certeza. Está explicado por que os convocou; quer que passem a cuidar de sua segurança pessoal. Clodoaldo parece entender que a ideia é convidá-los para substituir o capataz morto, o que gera a reação impaciente do patriarca, que supõe seus interlocutores não estarem entendendo a situação e, para a sua irritação, não se colocando no seu devido lugar de meros guarda-costas.

Trazendo novo rumo à conversa, o irmão revela que eles dois estiveram com o capataz no dia em que a sua morte se deu. Clodoaldo respira fundo. A tensão aumenta, pois se anuncia o momento em que veremos se definir o sentido das trocas de olhares, informações indiretas e reticências. Em verdade, é Seu Francisco quem precisa entender melhor o que se passa, e os irmãos Ihe trazem à lembrança uma data que em princípio não diz nada ao patriarca, mas diz muito a eles. Nesta data, foram mortos o pai e tio deles por ordem do senhor de engenho, "por causa de uma cerca". Eles eram crianças, mas se lembram muito bem. Conhecendo as regras do jogo, Seu Francisco se levanta enquanto os dois se aproximam prontos para cobrar a dívida. Corte seco, e saltamos para a casa de Bia, que está preparando suas bombinhas para uma espetacular explosão em série, forte o suficiente para iluminar o ambiente e, dado importante, para perturbar o cão do vizinho que faz seu protesto enquanto ela e as crianças tapam os ouvidos e se curvam como quem precisa de proteção diante do show que eles mesmos promovem. No detonar das bombas, o espectador ao final ouve um estampido diferente, mais forte, sinal de que os irmãos Nascimento liquidaram a fatura na sala do Seu Francisco. Está cumprido o plano de vingança.

\section{Epílogo}

Tendo instituído em seu território, na zona chique da grande cidade, as formas de poder e relações de classe sociais arcaicas, Seu Francisco encarnou 
a presença do passado no presente. Fez o contemporâneo recolher todas as camadas da história que encontram ali no bairro de Boa Viagem uma superposição dos tempos confirmada pelo desfecho da trama. Ao mesmo tempo, se revela, nesse último confronto, mais um encontro inesperado que vem retomar um mote narrativo muito presente no cinema brasileiro contemporâneo. Tal mote foi tecido sem pressa ao longo do filme e vem se ajustar ao que de intrigante se delineou nas maneiras e no fraseado de Clodoaldo, algo que encontrou sua contraparte somente na iminência do desfecho, quando o ar sisudo do irmão como que anunciou uma nova inflexão no enredo.

O essencial é que a rarefação, o escoamento do tempo, define a cadência do percurso marcado por premonições e momentos de estranheza anunciando uma revelação adiada. Num momento em que finais abertos, com interrogações sem resposta, já viraram quase que uma norma de época, o gesto de Kleber está na contracorrente. Assume o desfecho que nos fornece a chave de uma trama que nos convida a um retrospecto, atando o prólogo e a última cena com esse retorno literal de um protocolo de vingança que vem confirmar a permanência de uma ordem de relações do passado em pleno centro urbano imerso na ordem da sociedade capitalista de consumo, cujas relações de classe já são de outra ordem na lida com a desigualdade. A vingança que se consuma não é um gesto político, muito menos de superação das regras do jogo postas pela tradição. O lance corajoso, bem urdido, traz um senso de justiça e vale como uma vitória da astúcia do oprimido, que traz simpatia, mas seu teor vem completar o círculo de reposição do mundo arcaico de Seu Francisco.

Estamos aqui na camada em geral submersa de uma peculiar sobreposição de ritmos na atual conjuntura urbana, onde ainda se verifica a diferença, às vezes radical, entre o movimento acelerado da globalização e a persistência de estratos de tempo locais, compondo um quadro em que o pólo mais espetacular, emblema efetivo de nossa época, é a vida das metrópoles em seu estágio avançado de crescimento (inchaço). Este, raras vezes planejado, exibe seus efeitos nas variadas formas de convivência problemática entre os citadinos às voltas com um exasperante cotidiano, notadamente nas capitais dos Estados, dentro de um processo que se insere num campo transnacional de circulação, mas ainda dá lugar para experiências como esta que as personagens de $\mathrm{O}$ som ao redor radicalizam. 
No contexto da produção brasileira, o filme desloca a tônica do debate sobre a violência e as mazelas urbanas, em geral associadas à crise da família e focalizando uma juventude "sem pai", cuja condição social vivida nas favelas induz à entrada no crime organizado, como acontece em Cidade de Deus, de Fernando Meirelles (2001), entre outros. Kleber devolve a questão da violência ao autoritarismo da tradição patriarcal, de modo que não se trata apenas de culpar a urbanização selvagem porque dissolve a família, mas dar ênfase a outro ângulo do problema: mostrar que ele está na tradição senhorial-familiar dos de cima, que sobrevive, notadamente na relação com o outro de classe.

No início deste texto, comentei o quanto o cinema de Pernambuco, na sucessão destas gerações recentes, vem compondo um conjunto que apresenta fortes conexões, algo não encontrado com a mesma força em outros focos produtores. O filme de Kleber Mendonça Filho traz uma síntese em que o passado no presente, o paradigma patriarcal e as questões de classe se articulam de modo a animar uma recapitulação do percurso desse cinema no período da chamada retomada, assinalando suas constantes, tal como citei na abertura deste artigo.

O som ao redor tem essa notável capacidade de gerar um movimento retrospectivo, ou seja, "criar os seus precursores", sobrepondo à cronologia uma ordem de relações. Nesta, o diálogo entre as obras expõe de forma mais nítida uma configuração do campo quando surge aquela que, como ponto de convergência, acumulação de motivos e espécie de síntese, consolida uma nova percepção do conjunto. O foco recai naquele aspecto central do filme que destaca, de modo revelador, uma problemática que tem mobilizado cineastas que, guardadas as diferenças de estilo, exploram o motivo temático da permanência do passado no presente, pondo em cena as camadas de tempo que se acumulam na experiência contemporânea, esta mesma que resulta de uma modernização incompleta marcada pelas permanências daquele mundo do "homem cordial" que herdamos do Brasil colônia.

Ismail Norberto Xavier é professor Emérito da Escola de Comunicações e Artes da USP; leciona no Departamento de Cinema, Rádio e Televisão. É doutor em Teoria Literária e Literatura Comparada - FFLCH-USP e PhD em Cinema Studies, na New York University.

i-xavier@uol.com.br 


\section{Referências}

DUNKER, C. Mal-estar, sofrimento e sintoma: uma psicopatologia do Brasil entre muros. São Paulo: Boitempo, 2015.

HOLANDA, S. B. Raízes do Brasil. São Paulo: Companhia das Letras, 1997.

KOSELLECK, R. Estratos do tempo: estudos sobre história. Rio de Janeiro: Editora Contraponto/Editora PUC-Rio, 2014.

Artigo recebido em 10/12/2020 e aprovado em 01/02/2021. 